\title{
Editorial
}

\section{Is current treatment increasing asthma mortality and morbidity?}

Mortality and hospital admission rates for asthma have increased in most developed countries over the last 30 years. Many of these countries experienced an epidemic of deaths from asthma in the mid $1960 \mathrm{~s}^{1-3}$ and a further epidemic of deaths has been reported more recently in New Zealand. ${ }^{4}$ Hospital admissions have climbed rapidly in many countries since the mid 1960 s, especially in children..$^{5-8}$ Associated with these trends has been a substantial increase in sales of asthma drugs. ${ }^{9}$ These changes have occurred against the background of an apparent improvement in the treatment of asthma, ${ }^{10}$ the development of new drugs, ${ }^{11}$ better formulations and delivery systems, ${ }^{12}$ and increased understanding of the pharmacokinetics of the drugs used ${ }^{13}$ and of the pathogenesis of asthma. ${ }^{14}$ The paradox of improving treatment with increasing mortality and morbidity raises the possibility that changes in the prevalence and severity of the illness have occurred and leads to questions about the overall effectiveness of current management of asthma.

The cause of the epidemic of deaths from asthma seen in the mid 1960s in many countries was probably related to the introduction of a higher concentration isoprenaline inhaler, ${ }^{15}$ although this is still the subject of debate. ${ }^{316}$ In 1982 a further epidemic of asthma deaths in New Zealand was reported. ${ }^{4}$ Since then an increase in asthma mortality has been reported in England and Wales, ${ }^{17}$ Canada $^{18}$ and the United States. ${ }^{19}$ The changes in asthma mortality appear to be real and are not easily explained by changes in coding or death certification. ${ }^{4171820}$ Possible explanations include a change in prevalence or severity of the disease and a change in case fatality.

The increase in hospital admissions for asthma have been studied extensively, particularly in children. ${ }^{21}$ In the last 15 years hospital admissions for asthma in children have increased 6.6 fold in England and Wales and 10 fold in New Zealand. ${ }^{8}$ The increase is not explained by changes in the International Classification of Diseases coding or diagnostic transfer. ${ }^{521}$ As hospital admissions relate to events rather than individual patients the increase could represent an increase in either readmissions or number of patients. The figures indicate that readmissions have increased

Address for reprint requests: Dr E A Mitchell, Department of Paediatrics, School of Medicine, University of Auckland, Private Bag, Auckland 1, New Zealand. but overall the increase in admissions is principally due to an increase in the number of individual patients admitted each year. ${ }^{62}$

The increase in admissions and readmissions might be explained by changes in admission criteria, so that self referrals are encouraged and patients with milder asthma are admitted in the belief that such "open door policies" save lives.$^{23}$ Retrospective studies, however, suggest that the threshold for admission has not decreased or may even have increased, so that not only are there more patients but their asthma is at least as severe as it was in the past. ${ }^{24}{ }^{25} \mathrm{~A}$ recent study in New Zealand has documented an increasing number of children requiring ventilatory support for asthma, although this too could result from changes in the criteria used in initiating ventilation. ${ }^{26}$ The implication that $90 \%$ of children and $66 \%$ of adults (15-44 years) currently seen as inpatients in New Zealand could have been successfully managed in the community 15 years ago with the facilities that were available then seems unlikely, and provides further support for the belief that asthmatic episodes are becoming more frequent or severe or both.

There have been many studies of asthma prevalence in different countries and at different times, though the widely varying methods used make comparisons between different times or countries difficult. The diagnosis of asthma has been based on questionnaires, examination, lung function tests, bronchial challenge tests, or various combinations of these. In Birmingham "asthma prevalence" increased from $1.8 \%$ in $1957^{27}$ to $6.3 \%$ in $1975^{28}$; the change may in part at least reflect the change in questions asked in the two studies. In Lower Hutt, New Zealand, there was an increase in prevalence from $7 \cdot 1 \%$ in 1969 to $13.5 \%$ in 1982 in the same two intermediate schools on the basis of answers to the same question-"Has this child suffered from asthma?"29 30 Although these data suggest an increase in the prevalence of asthma, they may represent an improvement in disease labelling rather than a true change in the prevalence of asthma. The appearance of asthma in developing countries, well documented in Papua New Guinea (0.15\% in $1972^{31}$ to $7 \cdot 3 \%$ in $\left.1980^{32}\right)$ is highly suggestive of an increase in asthma prevalence. A general practitioner survey found an increase of about $80 \%$ in people consulting for asthma and hay fever $^{33}$ and, although again this could 
represent improved disease labelling, it could also reflect some increase in asthma prevalence. Even if asthma prevalence has doubled, however, it does not readily explain the substantial increase in admission rates.

The factors causing such a change are unknown. Known airborne allergens or pollution are unlikely to be responsible ${ }^{34}$ although new, unrecognised factors cannot be excluded. The difference in asthma prevalence between developed and developing countries has suggested that differences in dietary sodium may play a part. A positive correlation between table salt purchases and asthma mortality in both men and children, but not in women, was seen in regional data from England and Wales. ${ }^{35}$ This interesting hypothesis does not appear to explain the trends in annual mortality, however, as dietary sodium intake has decreased with time in England and Wales. ${ }^{36}$ Table salt may be a marker for other factors, yet unidentified.

The evidence suggests that any changes in the prevalence of asthma have been relatively small, yet there has been a dramatic increase in the number of patients with severe episodes requiring hospital admission and a further increase in asthma mortality, particularly in adults. What might be causing these changes?

Evidence of overreliance on sympathomimetic treatment has been seen in studies of both the epidemics of asthma deaths; such overreliance may have resulted in delays before more appropriate treatment was started and therefore indirectly increased the risk of death. ${ }^{37}{ }^{38}$ Mortality reviews have disclosed errors in management and failure to recognise the severity of the episode by the patients, their families, and their medical practitioners. Similarly, overreliance on beta agonists and failure in medical management may be factors in hospital admissions. It seems unlikely, however, that management of asthma is now worse than a decade ago or that this deterioration occurred simultaneously in several countries.

The correlation between increasing morbidity from asthma and sales of asthma drugs ${ }^{539}$ raises the possibility of a causal relation. Undoubtedly inhaled beta agonists have a beneficial effect in the treatment of acute asthmatic episodes. But could inhaled beta agonists given regularly make asthma worse or more "brittle" in the long term?

Tolerance to the bronchodilating action of beta agonists (tachyphylaxis) has been shown to occur in vitro and in vivo in animals and man in several studies. $^{39-41}$ Tachyphylaxis could lead to a worsening of the asthma in patients using beta agonists, though this hypothesis is not supported by most of the clinical data. ${ }^{42}$

Another earlier hypothesis was that beta agonists might produce fatal arrhythmias. This subject has been recently reviewed. ${ }^{43}$ Animal studies indicate tha high doses of beta agonists can produce arrhythmia\&? and myocardial necrosis. The evidence for similap effects in man is scanty. When selective beta agonist? are used intravenously arrhythmias are rarely $\tilde{a}^{\circ}$ problem in children or young adults. When these drugs are inhaled only small amounts of the drugs reaches the systemic circulation, so arrhythmias would be expected to be less of a problem. If, however, fatal arrhythmias were produced very occasionally bł inhaled beta agonists, then changes in the use of these drugs could result in changes in mortality, though suct an effect would not be detected in a prospective studis unless it was extremely large. The introduction of and overreliance on nebuliser treatment have beepo implicated, ${ }^{44}$ but this could account for at most $8 \%$ o $\overrightarrow{\widehat{\Phi}}$ the deaths seen in New Zealand. ${ }^{45}$ Recently it has been suggested that beta agonists combined with orat theophylline have an additive effect, which at higf doses may induce cardiac arrest, ${ }^{46}$ but no evidence for this was found in a detailed study. ${ }^{38}$

Could drug induced changes in bronchial hyperresponsiveness be responsible for the increase io asthma mortality and morbidity? The degree of bronchial hyperresponsiveness can be measured by using inhalation tests with agonists such as histamine ${ }^{47}$ anf methacholine. The degree of hyperresponsiveness correlates well with severity of asthma, although thene is a considerable range of asthma severity for any level of hyperresponsiveness. ${ }^{48}$ Three recent studies hav $\overrightarrow{8}$ shown that regular long term inhaled beta agonises produce an increase in bronchial hyperresponsivenes within 24 hours of stopping treatment. ${ }^{49-51}$ Some othe studies have failed to show this, possibly owing th inadequate sample size. In one of these studies the authors did not comment on the improvement in hyperresponsiveness seen two weeks after treatmen⿳亠口冋. was discontinued..$^{52}$ Vathenen et al also showed that after only two weeks' treatment with terbutaline the protection produced by terbutaline against histamine induced bronchoconstriction was reduced. ${ }^{51}$ Furthe studies are required to see whether there is reduced protection against provocative stimuli other tha histamine. The reduction in responsiveness to inhaled beta agonists during severe asthmatic episodes is well recognised and patients may then abandon then These studies indicate that a rebound in bronchial hyperresponsiveness occurs in these circumstances, which may make patients more vulnerable to astat matic stimuli and thus exacerbate their asthma. A though such an outcome is as yet hypothetical, it mas be advisable to tell asthmatic patients to continue to inhale beta agonists in the acute episode even if the appear not to be working. Additional instructions, such as starting oral prednisone $e^{33-5 s}$ and seekiris medical attention, are of course necessary. 


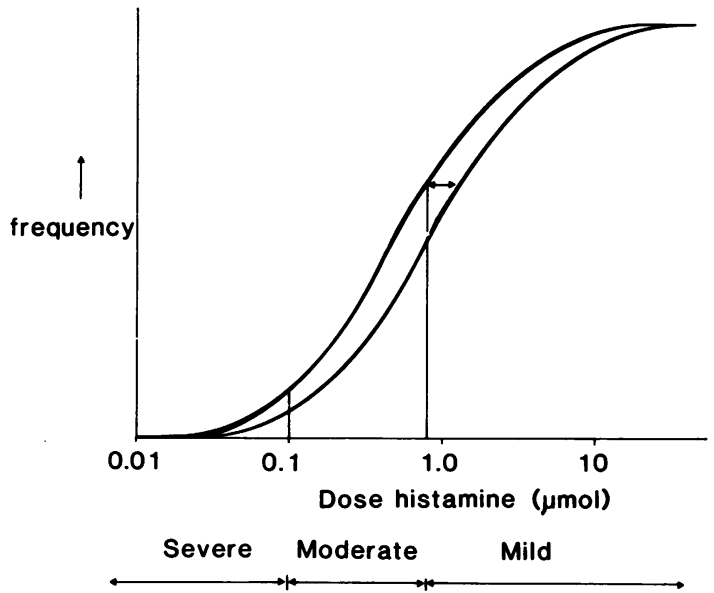

Frequency distribution of asthma severity as measured by the cumulative dose of histamine which causes a $20 \%$ fall in $F E V_{1}$. The small change in bronchial hyperresponsiveness $(\leftrightarrow)$ results in large changes in the proportion with severe asthma.

The changes in decreased protection or increased bronchial hyperresponsiveness after long term treatment with inhaled beta agonists may be of little consequence for the individual patient and may be undetectable in view of the natural variability in severity seen in asthma. When this deterioration in bronchial hyperresponsiveness is applied to the whole population of patients with asthma the change is potentially of major significance. This is illustrated by the figure, which shows the frequency distribution of asthma severity as measured by the cumulative dose of histamine that causes a $20 \%$ fall in FEV $\left(\mathrm{PD}_{20}\right)$. A very small change in bronchial hyperresponsiveness in the population results in a small increase in the number of patients with moderate asthma but a substantial increase in the proportion of patients in the severe category.

Whether or not this change in bronchial hyperresponsiveness is important can be resolved only by a large clinical trial in which asthmatic patients are randomised into groups receiving either beta agonists for regular inhalation or beta agonists to be inhaled sparingly. Earlier studies found slightly better peak flow and $F E V_{1}$ values in patients taking regular beta agonists, ${ }^{5657}$ and led to the recommendation that the first line of treatment for the ambulatory patient is regular inhaled beta agonists. ${ }^{13}$ The sample size in these studies has been too small, however, to detect any long term benefit or disadvantage of regular inhaled beta agonists, such as a change in the number of severe asthmatic episodes and admissions to hospital. Until such a study has been reported it seems prudent to avoid using regular high doses of inhaled beta agonists and to reserve these for symptomatic treatment. Symptoms necessitating frequent use of inhaled beta agonists should be seen as indicating a need to start or increase prophylaxis with inhaled corticosteroids or cromoglycate.

This work was supported by a grant from the Asthma Society (Auckland).

EA MITCHELL

Department of Paediatrics

University of Auckland and School of Medicine Auckland, New Zealand

\section{References}

1 Inman WHW, Adelstein AM. Rise and fall of asthma mortality in England and Wales in relation to use of pressurised aerosols. Lancet 1969;ii:279-85.

2 Fraser P, Doll R. Geographical variations in the epidemic of asthma deaths. Br J Prev Soc Med 1971;25:34-6.

3 Stolley PD. Asthma mortality: why the United States was spared an epidemic of deaths due to asthma. Am Rev Respir Dis 1972;105:883-90.

4 Jackson RT, Beaglehole R, Rea HH, Sutherland DC. Mortality from asthma: a new epidemic in New Zealand. Br Med J 1982;285:771-4.

5 Jackson RT, Mitchell EA. Trends in hospital admission rates and drug treatment of asthma in New Zealand. NZ Med J 1983;96:727-9.

6 Anderson HR. Increase in hospitalisation for childhood asthma. Arch Dis Child 1978;53:295-300.

7 Khot A, Burn R, Evans N, Lenney C, Lenney W. Seasonal variation and time trends in childhood asthma in England and Wales 1975-81. Br Med J 1984;289:235-7.

8 Mitchell EA. International trends in hospital admission rates for asthma. Arch Dis Child 1985;60:376-8.

9 Keating G, Mitchell EA, Jackson R, Beaglehole R, Rea $H$. Trends in sales of drugs for asthma in New Zealand, Australia and the United Kingdom, 1975-81. Br Med J 1984;289:348-51.

10 Hay IFC, Higenbottam TW. Has the management of asthma improved? Lancet 1987;ii:609-11.

11 Mann NP, Hiller EJ. Ipratropium bromide in children with asthma. Thorax 1982;37:72-4.

12 Milner AD. Bronchodilators in childhood asthma. In: Clark TJH, ed. Bronchodilator therapy: the basis of asthma and chronic obstructive airways disease management. Auckland: Adis Press, 1984:93-111.

13 Rebuck AS, Chapman KR. Asthma: 2. Trends in pharmacologic therapy. Can Med Assoc J 1987;136:483-8.

14 Holgate ST, Finnerty JP. Recent advances in understanding the pathogenesis of asthma and its clinical implications. $Q J$ Med 1988;66:5-19.

15 Stolley PD, Schinnar R. Association between asthma mortality and isoproterenol aerosols: a review. Prev Med 1978;7:519-38.

16 Cushley MJ, Tattersfield AE. Sudden death in asthma: discussion paper. J R Soc Med 1983;76:662-6.

17 Burney PGJ. Asthma mortality in England and Wales: 
evidence for a further increase, 1974-84. Lancet 1986;ii:323-6.

18 Jackson RJ, Sears MR, Beaglehole R, Rea HH. International trends in asthma mortality 1970-1985. Chest (in press).

19 Sly RM. Increases in deaths from asthma. Ann Allergy 1984;53:20-5.

20 Sears MR, Rea HH, Beaglehole R, et al. Asthma mortality in New Zealand: a two year national study. NZ Med J 1985;98:271-5.

21 Anderson HR. The epidemiological value of hospital diagnostic data. In: Bennett AE, ed. Recent advances in community medicine. Edinburgh: Churchill Livingstone, 1978:175-95.

22 Mitchell EA, Cutler DR. Paediatric admissions to Auckland Hospital for asthma from 1970-1980. NZ Med J 1984;97:67-70.

23 Crompton GK, Grant IWD, Bloomfield P, Edinburgh emergency asthma admission service: report on 10 years' experience. Br Med J 1979;ii:1199-201.

24 Anderson HR, Bailey P, West S. Trends in the hospital care of acute childhood asthma 1970-8: a regional study. Br Med J 1980;281:1191-4.

25 Dawson KP. The severity of asthma in children admitted to hospital: a 20 year review. $N Z$ Med J 1987;100: $520-1$.

26 Dawson KP, Hickling KG, Mogridge N. Assistedventilation in severe childhood asthma. NZ Med $J$ 1988;101:236-8.

27 Smith JM. Prevalence and natural history of asthma in school children. Br Med J 1961;i:711-3.

28 Smith JM. The prevalence of asthma and wheezing in children. Br J Dis Chest 1976;70:73-7.

29 Milne GA. The incidence of asthma in Lower Hutt. $N Z$ Med J 1969;70:27-9.

30 Mitchell EA. Increasing prevalence of asthma. $N Z \mathrm{Med} J$ 1983;96:463-4.

31 Anderson HR. The epidemiological and allergic features of asthma in the New Guinea Highlands. Clin Allergy 1974;4:171-83.

32 Woolcock AJ, Dowse GK, Temple K, Stanley H, Alpers MP, Turner KJ. The prevalence of asthma on the South-Fore people of Papua New Guinea. A method for field studies of bronchial reactivity. Eur J Respir Dis 1983;64:571-81.

33 Fleming DM, Crombie DL. Prevalence of asthma and hay fever in England and Wales. $\mathrm{Br}$ Med J 1987;294:279-83.

34 Perry GB, Chai H, Dickey DW, et al. Effects of particulate air pollution in asthmatics. Am J Publ Health 1983;73:50-6.

35 Burney P. A diet high in sodium may potentiate asthma. Epidemiological evidence for a new hypothesis. Chest 1987;91(suppl 6):143-8S.

36 Cummins RO. Recent changes in salt use and stroke mortality in England and Wales. Any help for the salthypertension debate? J Epidemiol Community Health 1983;37:25-8.

37 British Thoracic Society. Death from asthma in twn regions of England. Br Med J 1982;285:1251-5.

38 Sears MR, Rea HH, Rothwell RPG, et al. Asthma mortality: comparison between New Zealand and England. Br Med J 1986;293:1342-5.
39 Reed CE. New therapeutic approaches in asthma. Allergy Clin Immunol 1986;77:537-43.

40 Conolly ME, Davies DS, Dollery CT, George CF Resistance to beta-adrenoceptor stimulants (a possibe explanation for the rise in asthma deaths). $B r$ Pharmacol 1971;43:389-402.

41 Jenne JW. Whither beta-adrenergic tachyphylaxis? Allergy Clin Immunol 1982;70:413-6.

42 Tattersfield AE. Tolerance to beta-agonists. Bull Eu Physiopathol Respir 1985;21:1-5S.

43 Tattersfield AE, Britton JR. Beta-adrenoceptor agonists. In: Asthma: basic mechanisms and clinical managemes In: Barnes, Rogers, Thompson, eds.

44 Grant IWB. Asthma in New Zealand. $\mathrm{Br}$ Med 1983;286:374-7.

45 Sears MR, Rea HH, Fenwick J, et al. Seventy five deaths in asthmatics prescribed home nebulisers. $\mathrm{Br} \mathrm{Med}$ 1987;294:477-80.

46 Wilson JD, Sutherland DC, Thomas AC. Has the change to beta-agonists combined with oral theophylline increased cases of fatal asthma? Lancet 1981;i:1235-

47 Neijens HF, Hofkamp M, Degenhart HJ, Kerrebijn KR. Bronchial responsiveness as a function of inhaled histamine and the methods of measurement. Bull Exr Physiopathol Respir 1982;18:427-38.

48 Woolcock AJ, Yan K, Salome CM, Sedgwick CJ, Peat What determines the severity of asthma? Chest 1985;87(suppl 5):209-213S.

49 Krahn J, Koeter GH, vd Mark TW, Sluiter HJ, de Vrie K. Changes in bronchial hyperreactivity induced by weeks of treatment with anti asthmatic drugs fo patients with allergic asthma: a comparison betwe budesonide and terbutaline. J Allergy Clin Immuna 1985;76:628-36.

50 Kerrebijn KF, van Essen-Zandvliet EEM, Neijens $\rightrightarrows$ Effects of long term treatment with inhaled corticos teroids with beta-agonists on bronchial responsiveness in asthmatic children. $J$ Allergy Clin Immunim 1987;79:653-9.

51 Vathenen AS, Knox AJ, Higgins BG, Britton JB, Tattersfield AE. Rebound increase in bronchial re ponsiveness after treatment with inhaled terbutaline. Lancet 1988; i:554-8.

52 Peel ET, Gibson GJ. Effects of long-term inhaled sal butamol therapy on the provocation of asthma by histamine. Am Rev Respir Dis 1980;121:973-8.

53 Deshpande A, McKenzie SA. Short course of steroids in home treatment of children with acute asthma. $\mathrm{Br} M$ J 1986;293:169-71.

54 Harris JB, Weinberger MM, Nassif E, Smith G, Milave G, Stillerman A. Early intervention with short courses of prednisone to prevent progression of asthma na ambulatory patients incompletely responsive if bronchodilators. J Pediatr 1987;110:627-33.

55 Storr J, Barrell E, Barry W, Lenney W, Hatcher G. Effet of a single oral dose of prednisolone in acute childho gd asthma. Lancet 1987; i:879-82.

56 Lenney W, Milner AD, Hiller EJ. Continuous añd intermittent salbutamol tablet administration in as matic children. Br J Dis Chest 1979;73:277-81.

57 Shepherd GL, Hetzel MR, Clark TJ. Regular vers symptomatic aerosol bronchodilator treatment of asthma. Br J Dis Chest 1981;75:215-7. 